\section{CHRIS DEERY: 'THE HALL TECHNIQUE WILL REVOLUTIONISE CHILDREN'S DENTISTRY'}

\author{
Chris Deery is Professor of Paediatric Dentistry at Sheffield University. His research \\ interests are cariology, evidence-based dentistry and child focused research.
}

\section{What made you choose paediatric dentistry?}

When I first graduated I went to work in general dental practice and found the interaction with children really rewarding. But I realised that there was a lot I didn't know about paediatric dentistry so I did a masters at Bristol to learn more. From there I went on to specialist training in Dundee.

Paediatric dentistry presents a lot of challenges: you've got to treat pre-cooperative and anxious children and adolescents, special needs children, sick children, dental trauma and those with developmental abnormalities. Every child is different and their needs are different.

It is really nice when the children get on with you. I think that anyone who goes into paediatric dentistry has an ability with children, because if the children don't like you you're not going to get anywhere. I particularly like treating anxious children. If you can get an anxious child or adolescent to accept treatment, that is really rewarding.

\section{What are you working on at the moment?}

$\mathrm{My} \mathrm{PhD}$ was on caries diagnosis and my main research is still on this topic. It is really vital to diagnose caries as early as we can. Traditionally, we diagnose caries at cavitation or in dentine when we place fillings. However, if you are going to actually be preventive in your approach you need to diagnose it earlier so I've been working with colleagues across the world on ICDAS - International Caries Detection and Assessment System. ICDAS uses meticulous visual caries diagnosis and includes stages of the disease that
'The problem must be getting a contract in place that actually delivers prevention' 


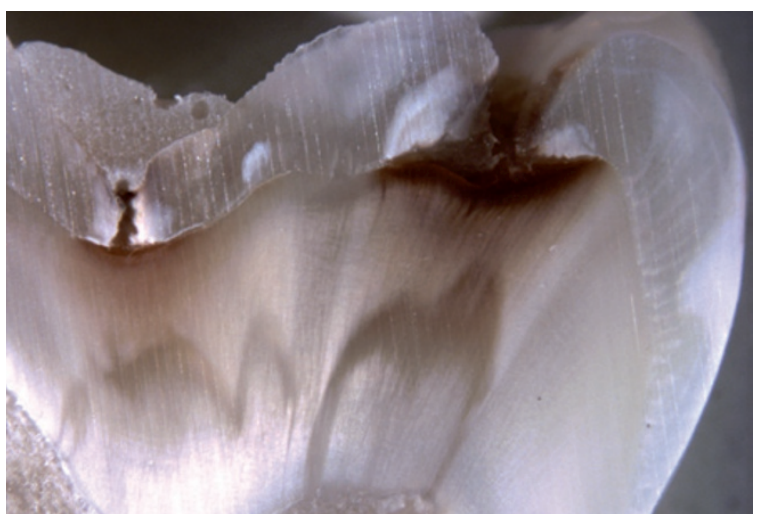

Fig. 1 'Beautiful' discoveries: a section of tooth under the microscope

the steps in research governance which, though highly important, make recruiting time consuming. That puts pressure on the practice so our biggest challenge is getting the number of patients required. We are about halfway now and we have until the middle of the year to get the patients we need.

\section{Have you ever changed your own practice because of something that you have discovered in your research?}

Yes, for example, we did a small project looking at what children thought about having their teeth fissure sealed. It turned out that they just hated the taste of the sealant which you can simply wipe away. This is a very little thing you can do to make the process better for the child.

\section{What is the most 'beautiful' discovery you have made?}

When we do the research on caries diagnosis we section the teeth (cut them up) and actually looking at teeth under the microscope - they are truly beautiful.

However, in terms of research, I did a Cochrane review with colleagues looking at the effectiveness of powered versus manual toothbrushing. We used the Cochrane methodology bringing together all the trials and analysed them to get a more powerful answer. That in its way was quite beautiful; it was pure. It got worldwide recognition outside dentistry; even lay magazines were interested in the results so it made me feel that we had produced a piece of research that people were noticing.

\section{What are you most proud of?}

Two things: one, I am Editor-inChief of the International Journal of
Paediatric Dentistry. And the other was the appointment to chair here in Sheffield and getting the chance to work with such brilliant colleagues.

What advice do you have for general dental practitioners for managing anxious child patients?

The first thing is never lie to them. Make it clear that what you say you are going to do is what you are going to do. Don't say something is not going to hurt when it is because that breaks the trust.

The other thing I advise is the old-fashioned "tell, show, do' because we know that works. Explain what you are doing in language they understand. It is really important that they know that they are in control. They need to know that they are able to stop you and get an explanation if they don't understand.

You must also make sure that the interaction is between you and the child, rather than between the parent and child, so that you are deciding how the conversation and explanation goes.

\section{Do you feel that there are adequate public health measures in the UK for the prevention of caries in children?}

First of all we have to recognise that we have a big problem with decay in the UK that we tend to forget. One of the most common reasons a child has a general anaesthetic (GA) is for the treatment of decay and I think that is quite appalling. Yet, we are doing things to help and I think the best example is Childsmile in Scotland (and similar schemes in other parts of the country, such as Designed to Smile in Wales and local schemes in England). The Childsmile scheme has involved supervised toothbrushing in nurseries, playgroups and primary school, applying fluoride varnish, applying sealants. Decay rates in Scotland are now falling at an incredible rate and it has to be a result of Childsmile. There is a need to copy these schemes in the places where they are not already being employed.

\section{What has been the biggest breakthrough in paediatric dentistry research in the last ten years?}

It has to be the discovery of the Hall technique. I think it's going to revolutionise, and already is revolutionising, children's dentistry. There is currently mixed knowledge among dentists about the technique and it depends where you are in the country. With anything new there is a 10-15 year rollout and so we are still in those stages.

\section{What is the greatest challenge relating to paediatric dentistry facing the UK DHs?}

The very high decay rates we still have amounting to a high burden in terms of the number of GAs and the fourth commonest reason a child turns up at A\&tE. Looking at the DHs, I know the new contract coming in in England is trying to aim at prevention, which is good. But they have tried to aim at prevention before so I suppose the problem must be actually getting a contract in place that actually delivers prevention.

\section{What would your three 'desert} island' research papers be?

Cueto E I, Buonocore M G. Sealing of pits and fissures with an adhesive resin: its use in caries prevention. 1967; 75: 121-128. This is the first paper on modern fissure sealants. Though it is a very old study it is a well-conducted and written-up paper. They covered an awful lot of ground. It was the first study on sealants and a big change was marked by its publication.

Chesters R K, Huntington E, Burchell C K, Stephen K W. Effect of oral care habits on caries in adolescents. Caries Res 1992; 26: 299304. This is the paper that said that if you don't wash your mouth out after you brush your teeth you will get less decay. It is a beautiful idea because it is a very simple change with a big reward. Indeed, if it had been my piece of research I'd have chosen it as my 'beautiful discovery'.

Mertz-Fairhurst E J, Curtis J W Jr, Ergle J W, Rueggeberg F A, Adair S M. Ultraconservative and cariostatic sealed restorations: results at year 10. J Am Dent Assoc 1998; 129: 55-66. One of the first studies to show that we can seal in decay and manage it that way rather than being destructive.

\section{What luxury would you bring to the island?}

Kitchen Secrets by Raymond Blanc. I considered asking for a cooker but then I thought 'I'm probably not allowed a cooker' so with that book at least I could dream about cooking.

\section{What would you do if you didn't work in dentistry?}

I'd actually be a historian. I read factual history books in my spare time.

\section{INTERVIEW BY RUTH DOHERTY}

Chris Deery will present a talk
entitled 'Can I seal it? Modern
caries management for young
people' on Friday 11 April at the
2014 British Dental Conference \&t
Exhibition in Manchester. Register
online: www.bda.org/conference.
Three-day conference passes are
free to all Expert and Extra BDA
members and these free passes can
be booked through the website.

